\title{
Cohesive zone modelling of Mode III delamination using the edge crack torsion test
}

\author{
H.A. Israr, K.J. Wong* and M.N. Tamin \\ Centre for Composites, Faculty of Mechanical Engineering, \\ Universiti Teknologi Malaysia, \\ 81310 UTM, Johor Bahru, Malaysia \\ *Email: kjwong@mail.fkm.utm.my \\ Phone: +6075534637; Fax: +6075566159
}

\begin{abstract}
In the experimental studies of mode III delamination using the edge crack torsion test, the crack initiation and propagation measurement are always difficult. This information could be obtained through numerical modelling. The objective of this study is to propose a guideline to model mode III delamination behaviour using cohesive elements. Finite element models of an edge crack torsion specimen were developed based on the data from the literature. The delamination behaviour of the specimen along the pre-crack, which was located at the mid-thickness location, was modelled using cohesive elements. Through parametric studies, it was found that for reliable numerical modelling, a mesh size of $0.5 \mathrm{~mm}$ was suggested, which provided three elements in the cohesive zone. As for the interface strength, it was recommended to choose $80 \mathrm{MPa}$. In addition, a viscosity parameter of $1 \times 10^{-3}$ was found to be a good choice for reasonable computational time and converged numerical results. Besides, the interface stiffness was suggested to be $4 \times 10^{6}$ $\mathrm{MPa} / \mathrm{mm}$. Furthermore, the fracture process zone contour revealed that the delamination was started at a normalised location of approximately 0.7 . Not only that, the fracture energy and strain distribution plots have shown the delamination was mode III dominated within the normalised distance of $0.34-0.86$. The results from this study suggested that cohesive zone modelling is a useful method for the detailed analysis of the mode III delamination of an ECT specimen. The numerical modelling approach suggested from this study could be applied to ECT specimens at various different initial crack lengths. It also has the potential to be used to simulate the mode III delamination of other various types of laminated composites.
\end{abstract}

Keywords: Interlaminar fracture; Mode III; edge crack torsion; cohesive zone modelling.

\section{INTRODUCTION}

In the studies of the delamination of composite laminates, mode III delamination has been recognised to be important due to its contribution to edge delamination [1]. The recent testing methods on mode III delamination include the modified split cantilever beam (MSCB) [2, 3], modified edge crack torsion (MECT) (which is still commonly known as edge crack torsion (ECT)) [4, 5], six ECT (6ECT) [6], modified shear torsion bending (MSTB) [7], which was initially designed for mixed-mode I+II+III delamination [8], split-shear torsion (SST) [9] and newly designed torsional tests [10]. Among the above 
mentioned tests, the edge crack torsion test is currently under evaluation by the American Society for Testing and Materials (ASTM) to be standardised [11]. The advantages of the edge crack torsion test include pure mode III delamination in the middle region of the specimen and negligible friction between the delaminated surfaces [12]. However, during the experimental testing, the initiation and propagation of the crack of the edge crack torsion specimen are not easily captured from the edges. This information could be obtained through numerical analyses.

The common numerical modelling approaches for the delamination of composite laminates are the virtual crack closure technique (VCCT) and the cohesive zone model (CZM) [13]. The VCCT has been commonly employed by various researchers to simulate the mode III delamination of carbon/epoxy [6, 14-16] and glass/epoxy [3, 5, 17-20] composite laminates. Nevertheless, in recent years, the CZM has gained its popularity in simulating the delamination behaviour of laminated composites. Its major advantage over the VCCT is the ability to predict both the onset and non-self-similar propagation of delamination without needing a pre-crack [21]. However, the CZM has been used more widely encountered in simulating mode I, mode II and mixed-mode I+II delamination behaviour [22-24]. It is comparatively less common to be employed in mode III delamination $[6,25,26]$. Furthermore, in the above mentioned three references, the choice of the cohesive parameters (element size, interface strength, viscosity parameter and interface stiffness) was not described. In this respect, there is a need to conduct a detailed parametric study of the cohesive parameters on mode III delamination of the edge crack torsion (ECT) specimen. The objective of this study is to suggest guidelines to select a suitable range for the cohesive parameters to simulate the delamination behaviour of the ECT specimens. The experimental result from the literature [15] was used. Through parametric studies, guidelines for the parameter selection for mode III delamination using the ECT test were proposed. Subsequently, the damage initiation and propagation profiles were also plotted and compared with the fracture energy distribution. Finally, the strain distributions in the ECT specimen were presented.

\section{NUMERICAL MODELLING}

\section{Cohesive Zone Model for Pure Tearing Mode Failure}

In this study, a cohesive element [27] was employed to simulate the delamination between the plies adjacent to the pre-crack. This type of element considers only out-of-plane stress components, and is generally known as the interface element. Since the present study focused on the mode III interlaminar fracture, only the formulation for delamination in the tearing mode is discussed. Consider an eight-node three-dimensional cohesive element that is subjected to loading as shown in Figure 1. Before any delamination damage occurs, the traction separation behaviour is assumed to be linear elastic. At any instant, the element is experiencing a relative displacement between the upper, $u_{I I I, u p}$ and lower, $u_{\text {III, low }}$ nodes, which is denoted as $\delta_{I I I}$ and is stored as the corresponding displacement at the integration point. For uncoupled shear traction, the constitutive behaviour is given as:

$$
t_{I I I}=k_{I I I} \delta_{I I I}
$$

where $t_{I I I}$ is the traction (stress) and $k_{I I I}$ is the interface stiffness (stiffness per unit thickness of the cohesive element). The subscript III refers to the tearing mode. 


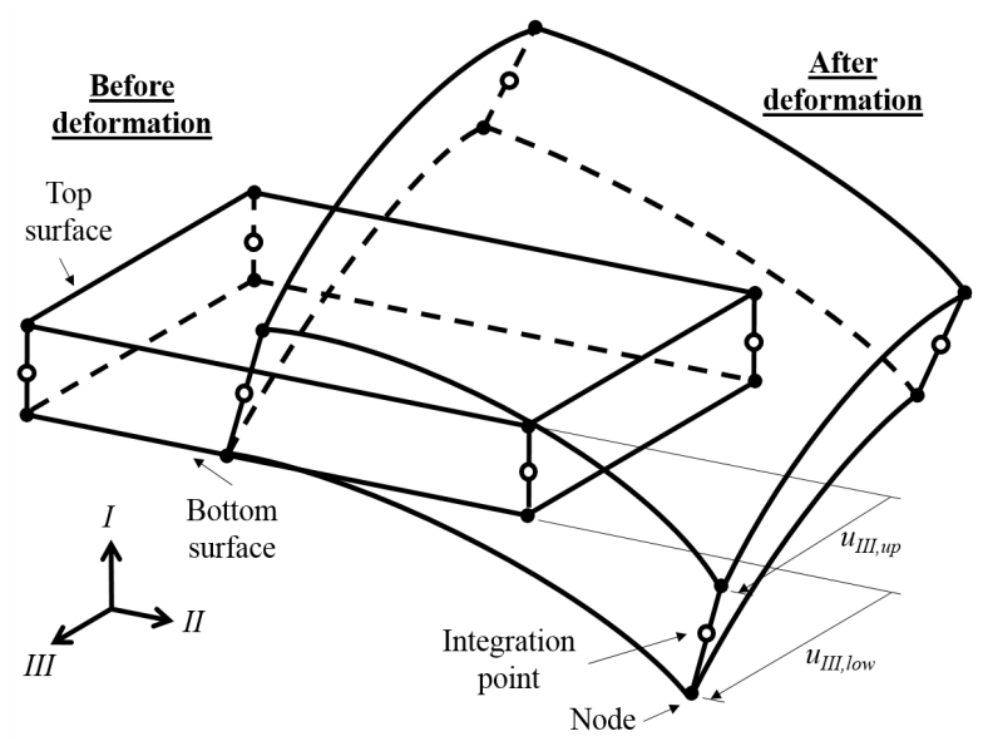

Figure 1. Schematic diagram of a three-dimensional cohesive element.

Interface damage initiation is governed by a quadratic nominal stress criterion. For pure mode III, it is written as:

$$
\left\{\frac{t_{I I I}}{t_{u, I I I}}\right\}^{2}=1
$$

where $t_{u, I I I}$ is the interlaminar strength in the tearing direction, which could be reduced to the maximum nominal stress criterion for this particular case, where the traction ratio on the left is not squared.

Delamination starts to occur at a material point of the interface when the quotient of the nominal stress ratio reaches unity. Subsequently, damage evolution occurs. In this study, the linear damage evolution law was used as described in Figure 2.

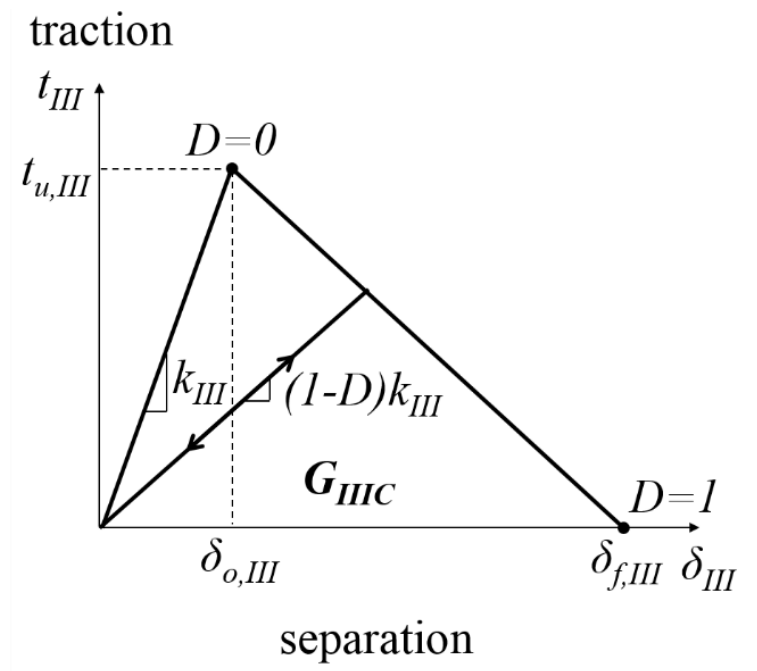

Figure 2. Schematic diagram of the bilinear traction separation law. 
The damage parameter, $D$ for the linear softening behaviour is written as:

$$
D=\frac{\delta_{f, I I I}\left(\delta_{I I I}-\delta_{o, I I I}\right)}{\delta_{I I I}\left(\delta_{f, I I I}-\delta_{o, I I I}\right)}
$$

where $\delta_{o, I I I}$ and $\delta_{f, I I I}$ refer to the relative displacement at damage onset and total failure. Linear softening was adopted due to its simplicity and accuracy compared to other traction-separation laws such as the exponential law [27].

During damage evolution, the constitutive behaviour of the interface is then calculated based on the following equation:

$$
t_{I I I}=(1-D) k_{I I I} \delta_{I I I}
$$

The damage evolution zone is governed by the dissipated energy due to damage, which is represented by the area under the curve of traction-separation. With the computed relative displacement $\delta_{I I I}$ at each iteration, $D$ could be calculated. The damage variable, $D$ is then updated into the stiffness matrix in Equation (4) and the traction, $t_{I I I}$ is updated. Subsequently, the corresponding mode III fracture energy, $G_{I I I}$ could be calculated and compared with $G_{I I I C}$. When the total fracture energy is equivalent to the fracture toughness $\left(G_{I I I}=G_{I I I C}\right), D=1$ and the material point is completely damaged.

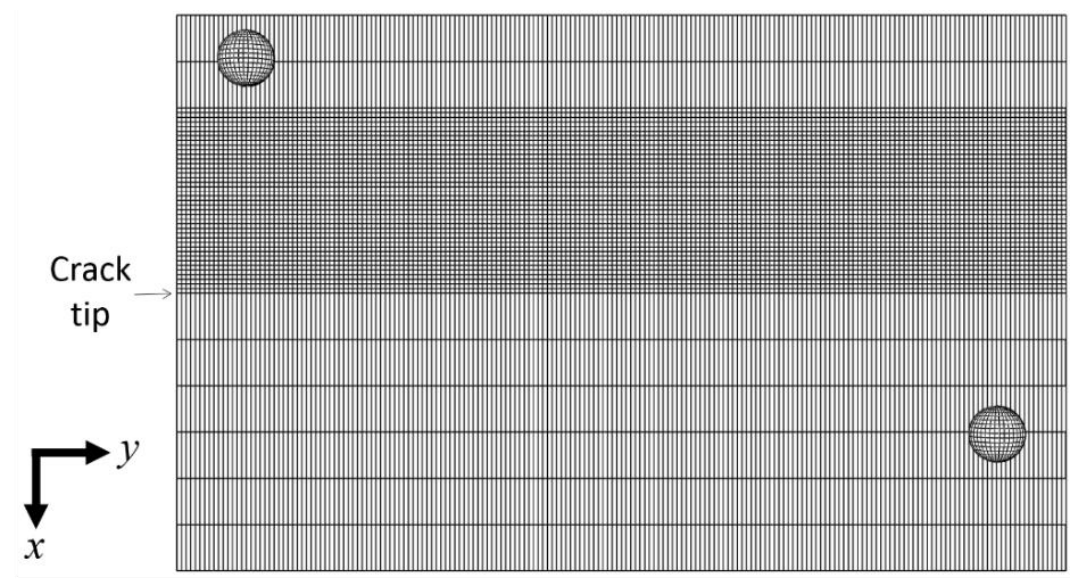

(a)

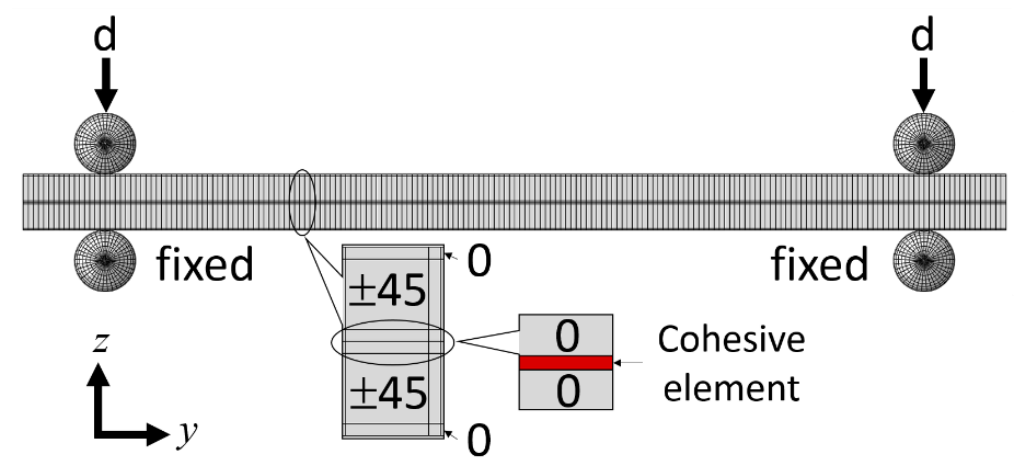

(b)

Figure 3. Finite element model of the ECT specimen: (a) top view; (b) front view. 


\section{Finite Element Modelling}

The finite element models were developed based on the information from the literature [15]. The material was a Texipreg T300/HS 160 REM carbon/epoxy composite with the lamina properties listed in Table 1 below. Figure 3 shows the finite element model of the ECT specimen, with the stacking sequence of $\left[0 /(-+45)_{4} /(+-45)_{4} / 0\right]_{\mathrm{s}}$. The two bottom spheres were fixed and the vertical displacement was imposed by the two upper spheres. The two mid- and outer-plies ( 0 plies) were modelled as single layers, whereas all other 45 plies were modelled by one element in the thickness direction. The composite layers were modelled using 8-node continuum shell elements (SC8R). As for the mid-plane interface, 8-node cohesive elements (COH3D8) were prescribed to simulate the delamination behaviour. Cohesive elements were modelled with $1 \mu \mathrm{m}$ thickness in order to avoid interpenetration [28]. The input for the pure-mode fracture toughness for cohesive elements were $G_{I C}=0.25 \mathrm{~N} / \mathrm{mm}, G_{I I C}=0.8 \mathrm{~N} / \mathrm{mm}$ and $G_{I I I C}=0.9 \mathrm{~N} / \mathrm{mm}$ [15].

Table 1. Lamina properties of the Texipreg T300/HS 160 REM carbon/epoxy composite[15].

\begin{tabular}{cccccc}
\hline $\mathrm{E}_{1}(\mathrm{GPa})$ & $\mathrm{E}_{2}(\mathrm{GPa})$ & $\mathrm{G}_{12}(\mathrm{GPa})$ & $\mathrm{G}_{13}(\mathrm{GPa})$ & $\mathrm{G}_{23}(\mathrm{GPa})$ & $v_{12}$ \\
\hline 130.0 & 8.2 & 4.1 & 4.1 & 4.1 & 0.27 \\
\hline
\end{tabular}

\section{Guidelines of Cohesive Parameter Selection}

The four parameters necessary to be considered for accurate cohesive zone modelling are element size $\left(l_{e}\right)$, interface strength $\left(t_{u, I I I}\right)$, viscosity parameter $\left(D_{v}\right)$ and interface stiffness $\left(k_{I I I}\right)$. The descriptions of the following parameters and their selection are as follows:

The element size, $l_{e}$ is an important parameter because a refined enough mesh in the cohesive zone allows for the accurate prediction of the traction in front of the crack tip. Based on the past studies using three-dimensional cohesive elements, researchers generally chose element size between $0.125-1 \mathrm{~mm}[29,30]$. A larger range of 0.25-2.5 $\mathrm{mm}$ of mesh size was considered in this study for a reasonable computational time. The interface strength is influenced by the resin strength [22]. A relatively high but lower than the physical value should be taken for an improved simulation at a relatively coarser mesh [29]. The parametric study was performed in the range of the tensile strength of the epoxy (40-100 MPa) [31]. This is also the same range of values used by various researchers as summarised earlier [22]. Viscous regularisation is introduced in order to avoid the termination of the computational routine due to the numerical instability caused by material softening behaviour. An appropriate value of the viscosity parameter improves the convergence of the analysis, but does not compromise the results to a notable extent. Hence, it is essential to choose an optimised viscosity parameter to obtain convincing results. A range from $1 \times 10^{-6}$ to $1 \times 10^{-1}$ was found from the literature $[22,32,33]$. In this study, a smaller range of the viscosity parameter between $1 \times 10^{-5}-1 \times 10^{-2}$ was considered.

Interface stiffness is basically not a physical parameter [22], since the out-of-plane stiffness of a very thin layer is not feasible to be characterised through experiments. In this study, the approach shown by Equation (5) was adopted, where $E_{m}$ is Young's modulus of the resin (taken as $4 \mathrm{GPa}$ based on the range 3-6 GPa [31]) and $h_{c e}$ is the thickness of the cohesive element $(1 \mu \mathrm{m})$. This approach is similar to the one mentioned by Allix and Blanchard [34] except that they used out-of-plane stiffness $E_{3}$ instead of $E_{m}$. This study used $E_{m}$ because both $E_{3}$ and $E_{m}$ are usually falling in the similar range, and $E_{m}$ is much easier to be determined experimentally. For $E_{3}$, this is generally assumed to be equal to $E_{2}$. Thus, the initial estimation of $k_{I I I}$ was $4 \times 10^{6} \mathrm{MPa} / \mathrm{mm}$. This is in the similar 
range of the values generally used by researchers [22, 29, 30, 35]. To study the effects of interface stiffness on the numerical force-displacement response, the range between $4 \times 10^{5}-4 \times 10^{8} \mathrm{MPa} / \mathrm{mm}$ was considered. Table 2 summarises the range of the cohesive parameters considered in this study.

$$
k_{I I I}=\frac{E_{m}}{h_{c e}}
$$

Table 2. Parametric studies of the cohesive parameters.

\begin{tabular}{ll}
\hline \multicolumn{1}{c}{ Cohesive parameters } & \multicolumn{1}{c}{ Range } \\
\hline Element size, $l_{e}$ & $0.25-2.5 \mathrm{~mm}$ \\
Interface strength, $t_{u, I I I}$ & $40-100 \mathrm{MPa}$ \\
Viscosity parameter, $D_{v}$ & $1 \times 10^{-5}-1 \times 10^{-2}$ \\
Interface stiffness, $k_{I I I}$ & $4 \times 10^{5}-4 \times 10^{8} \mathrm{MPa} / \mathrm{mm}$ \\
\hline
\end{tabular}

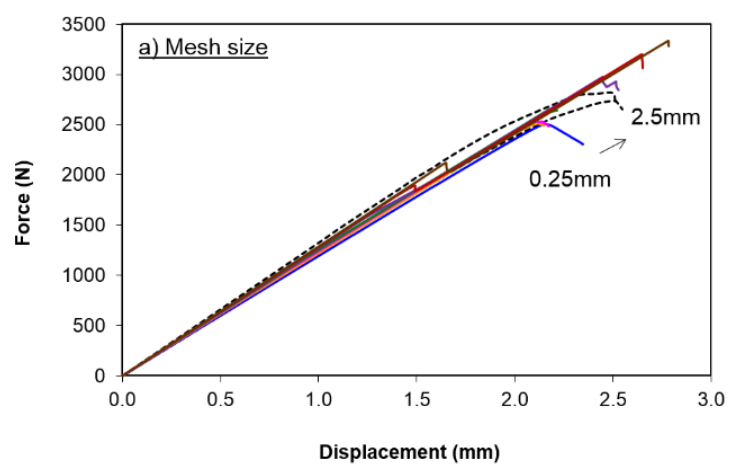

(a)

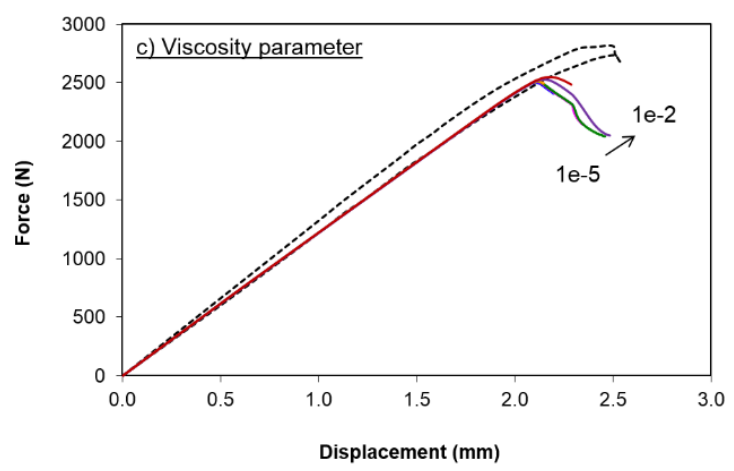

(c)

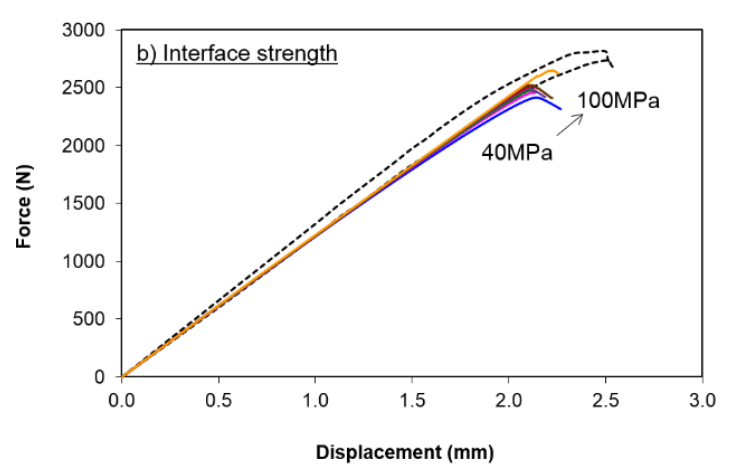

(b)

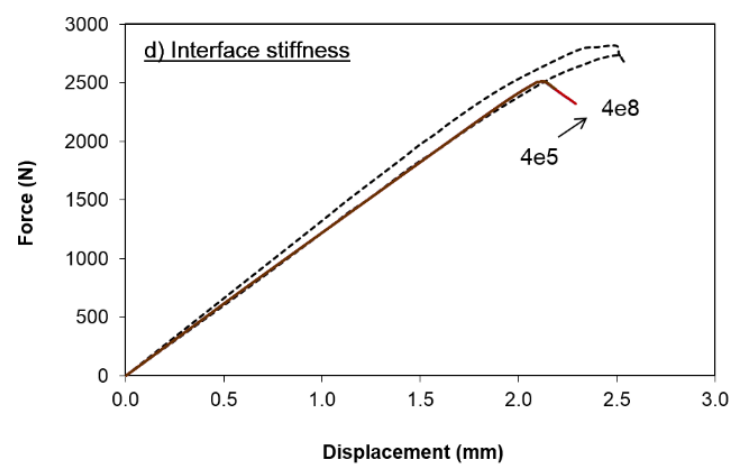

(d)

Figure 4. Influence of (a) mesh size; (b) interface strength; (c) viscosity parameter and (d) interface stiffness on the force-displacement responses.

\section{RESULTS AND DISCUSSION}

\section{Influence of Cohesive Parameters}

Figure 4 compares the experimental and numerical force-displacement curves of the ECT specimen. It could be observed from Figure 4(a)-(d) that the cohesive parameters had a 
negligible effect on the slope of the force-displacement curves. Nevertheless, a certain variation was found in the peak load. Figure 4(a) illustrates that the peak load increased with the mesh size. Specifically, when the mesh size was $1.5 \mathrm{~mm}$ and above, the numerical peak loads have exceeded the experimental ones. As for the interface strength, this was also reported to follow an increasing trend (Figure 4(b)). Up to $100 \mathrm{MPa}$, the numerical to experimental peak load ratio was 0.94. In addition, Figure 4(c) indicates that the increasing viscosity parameter has increased the numerical peak load as well. Similar to the interface strength, the numerical peak loads were always lower compared to the experimental values. A slight increment in the numerical peak load was noticed with the increment in the interface stiffness (Figure 4(d)). However, the difference was negligible. The detailed comparison among the numerical peak loads was therefore carried out in the following.

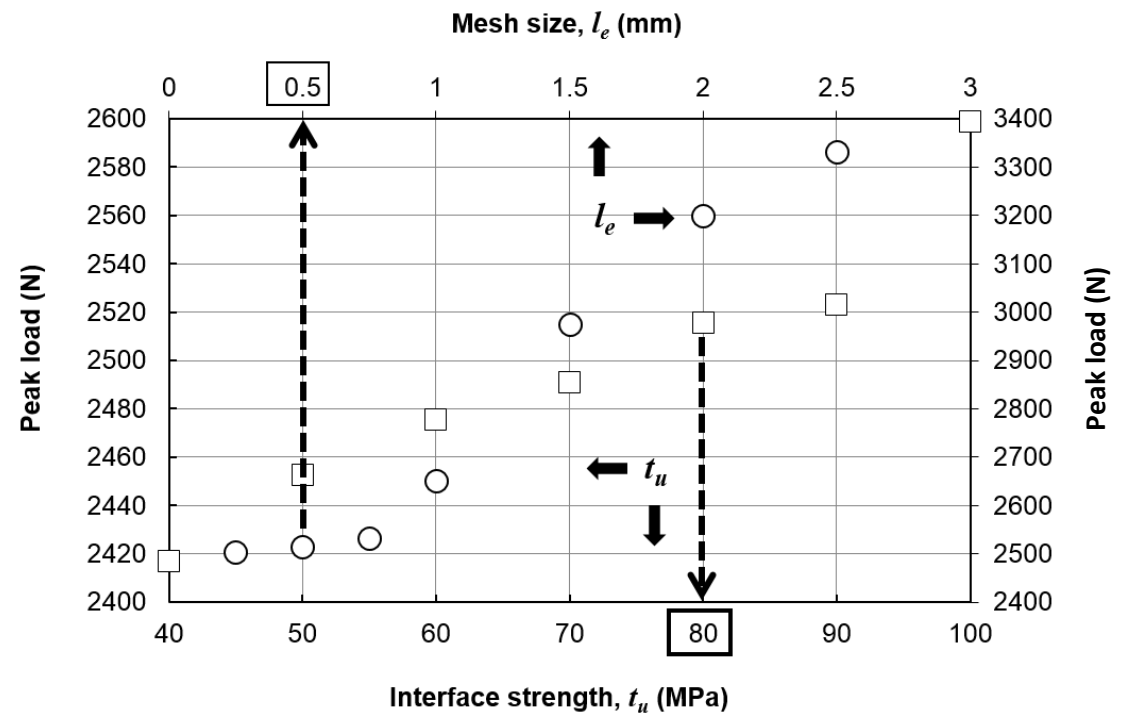

(a)

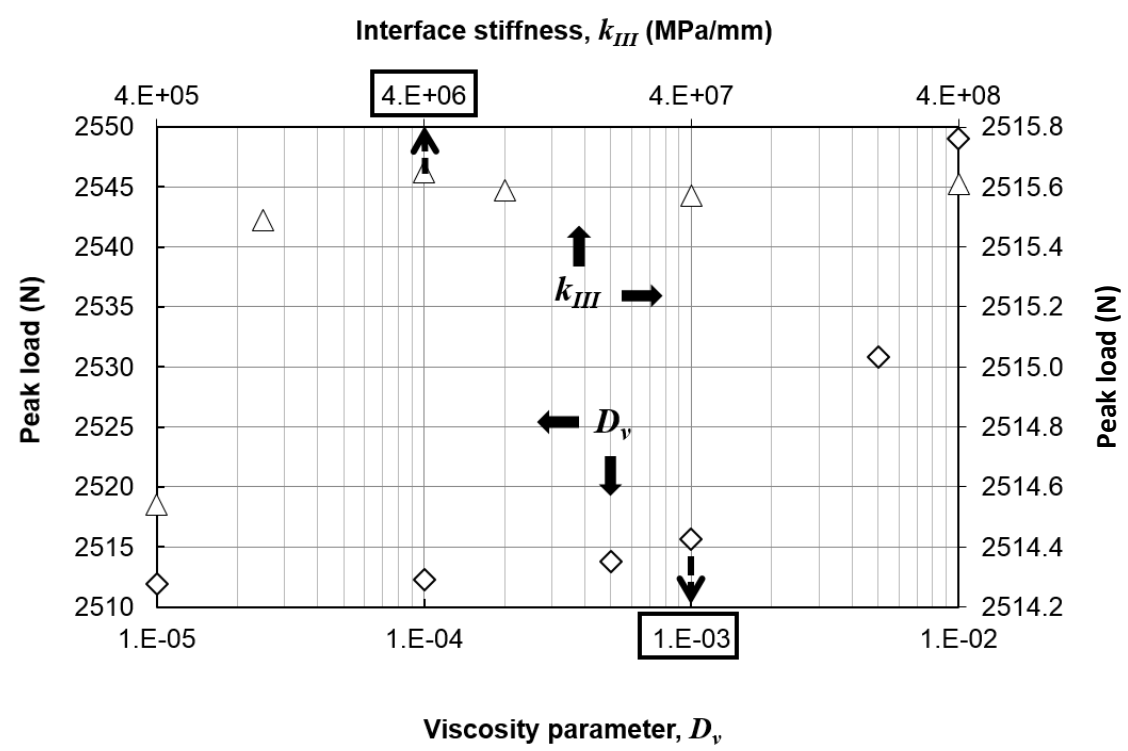

(b)

Figure 5. Comparison between the (a) mesh size and interface strength; and (b) viscosity parameter and interface stiffness on the numerical peak loads. 
From Figure 5(a), it was found that a mesh size of $0.5 \mathrm{~mm}$ and below is recommended. In addition, the interface strength was noticed to converge up to $80 \mathrm{MPa}$. As for the viscosity parameter, Figure $5(\mathrm{~b})$ depicts that a value of $1 \times 10^{-3}$ and below was a good choice for the converged result. A further decrement in the viscosity parameter did not vary the numerical peak load for more than $1 \%$; however, it would significantly increase the computation time. This was similar to a recent study on the three-dimensional modelling of mode II delamination using the CZM [36]. Furthermore, the interface stiffness did not seem to be sensitive within the studied range. This was because the initial linear elastic region of the traction-separation response was relatively small compared to the damage propagation region. Hence, the value of $4 \times 10^{6} \mathrm{MPa} / \mathrm{mm}$ was a good choice because it could be easily estimated using Equation (5). This was also in the similar range of the values generally used by researchers [22, 29, 30, 35]. From the above parametric studies, the suggested cohesive parameters for accurate simulation with reasonable computational time were $l_{e}=0.5 \mathrm{~mm}, t_{u, I I I}=80 \mathrm{MPa}, D_{v}=1 \times 10^{-3}$ and $k_{I I I}=4 \times 10^{6}$ $\mathrm{MPa} / \mathrm{mm}$. This set of cohesive parameters was found to be within the similar range as suggested by other researchers on mode I, mode II and mixed-mode I+II loadings [22, 29, 36]. Nevertheless, it should be noted that this set of cohesive parameters was particularly suggested for the T300/HS 160 REM carbon/epoxy composite. For different types of composite systems such as kenaf [37, 38], napier [39, 40], jute and hemp [41], the cohesive parameters are necessary to be evaluated again.

\section{Determination of the Cohesive Zone Length}

The length of the first fully developed cohesive zone is defined as the cohesive zone length, $L_{c z, f}$. In other words, the numerical $L_{c z, f}$ refers to the distance between the first element at the crack tip, which experiences total damage $(D=1)$, and the element in the case of which damage initiation is just attained $(D=0)$. It is important to have a sufficient number of cohesive elements in the cohesive zone to ensure accurate simulation results. Hence, the minimum number of cohesive elements, $N_{e}$, is another important parameter that is expressed as:

$$
N_{e}=\frac{L_{c z, f}}{l_{e}}
$$

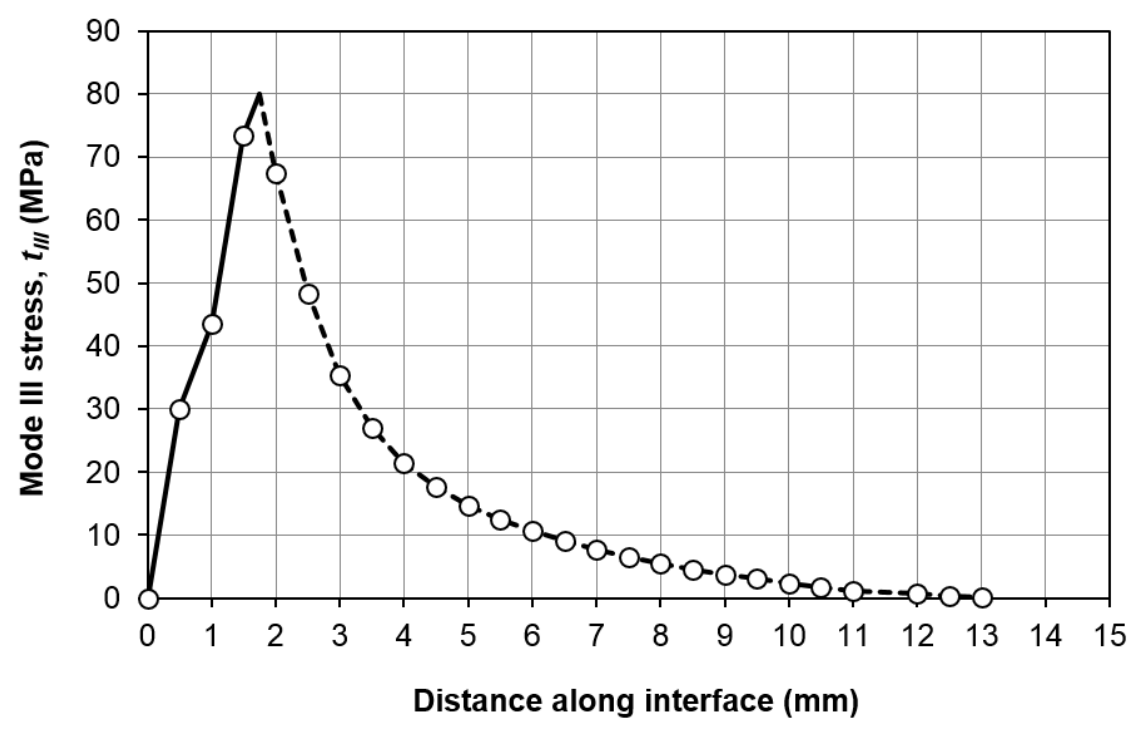

Figure 6. Stress distribution of the first fully developed cohesive zone. 
Figure 6 plots the stress distribution of the first fully developed cohesive zone from the results obtained using the suggested cohesive parameters. The peak stress was reasonable to be slightly extrapolated to $80 \mathrm{MPa}$, which was the interface strength input to the model. It was also the instant where the damage was initiated (Equation (2)). Before the peak load was attained, the element behaved linear elastically according to Equation (1). Beyond that, the damage propagation occurred and the stress decreased progressively according to Equation (4). It is observed that $L_{c z, f}$ was $1.5 \mathrm{~mm}$, which means that there were 3 cohesive elements within the cohesive zone. This is consistent with the recommendations by other researchers, where at least 2-3 cohesive elements are needed in the cohesive zone for accurate simulations [13, 29].

\section{Crack Front and Fracture Process Zone Profiles}

The crack front (CF) refers to the region where the cohesive elements have attained total failure $(D=1)$. The fracture process zone (FPZ) is the region where the cohesive elements have experienced damage initiation $(0 \leq D<1)$. Sometimes, it is also known as the cohesive zone. The definition of the damage parameter, $D$ is to be referred to Equation (4). The CF and FPZ contours of the ECT specimen were plotted in Figure 7. It could be seen that the crack propagation was not uniform. This implies the inaccuracy of the assumption of a uniform crack growth between the spheres [25]. Damage was firstly initiated and propagated at the normalised distance of approximately 0.7 , which is at the similar region observed by other researchers [25]. At peak load, the crack has propagated $(D=1)$ for approximately $2.8 \mathrm{~mm}$, whereas the damage initiation $(0 \leq D<1)$ has reached $3.2 \mathrm{~mm}$.

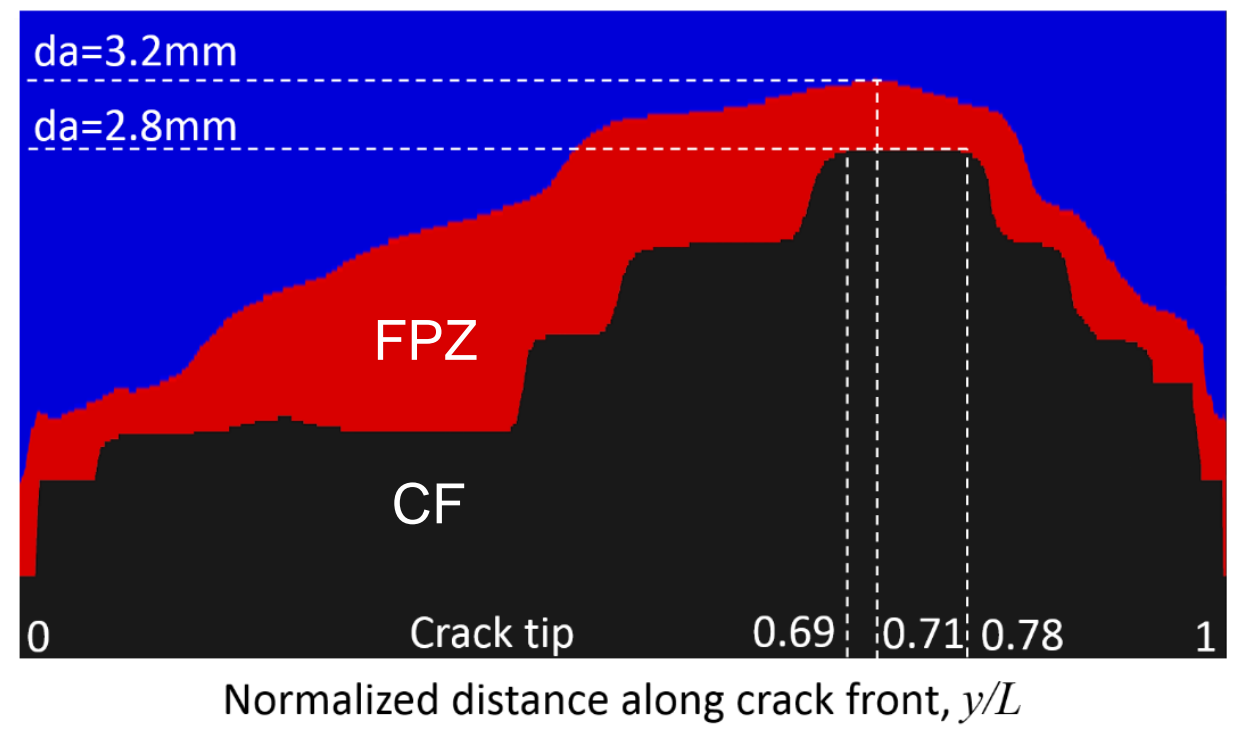

Figure 7. Crack front and fracture process zone along the crack front.

The fracture energy distribution, $G_{C}$ along the crack front at peak load was presented in Figure 8. To investigate the contribution of each mode in the delamination, the mode II and mode III strains, $\delta_{I I}$ and $\delta_{I I I}$ at peak load were plotted. It could be noticed that mode III was mainly dominated between the normalised distance of 0.34-0.86. It was in accordance to what has been reported by other researchers, where ECT test has the advantage of having pure mode III in the region between the loading and support pins [5, $14,15,17,25]$. In addition, it is worth to note that the normalised location near 0.34 was also the location with the minimal mode II component. The mode II component was larger 
than the mode III component at approximately only $1.5 \%$ of the normalised distance from the left edge. Hence, it is reasonable to regard the ECT test as a pure mode III fracture toughness test.

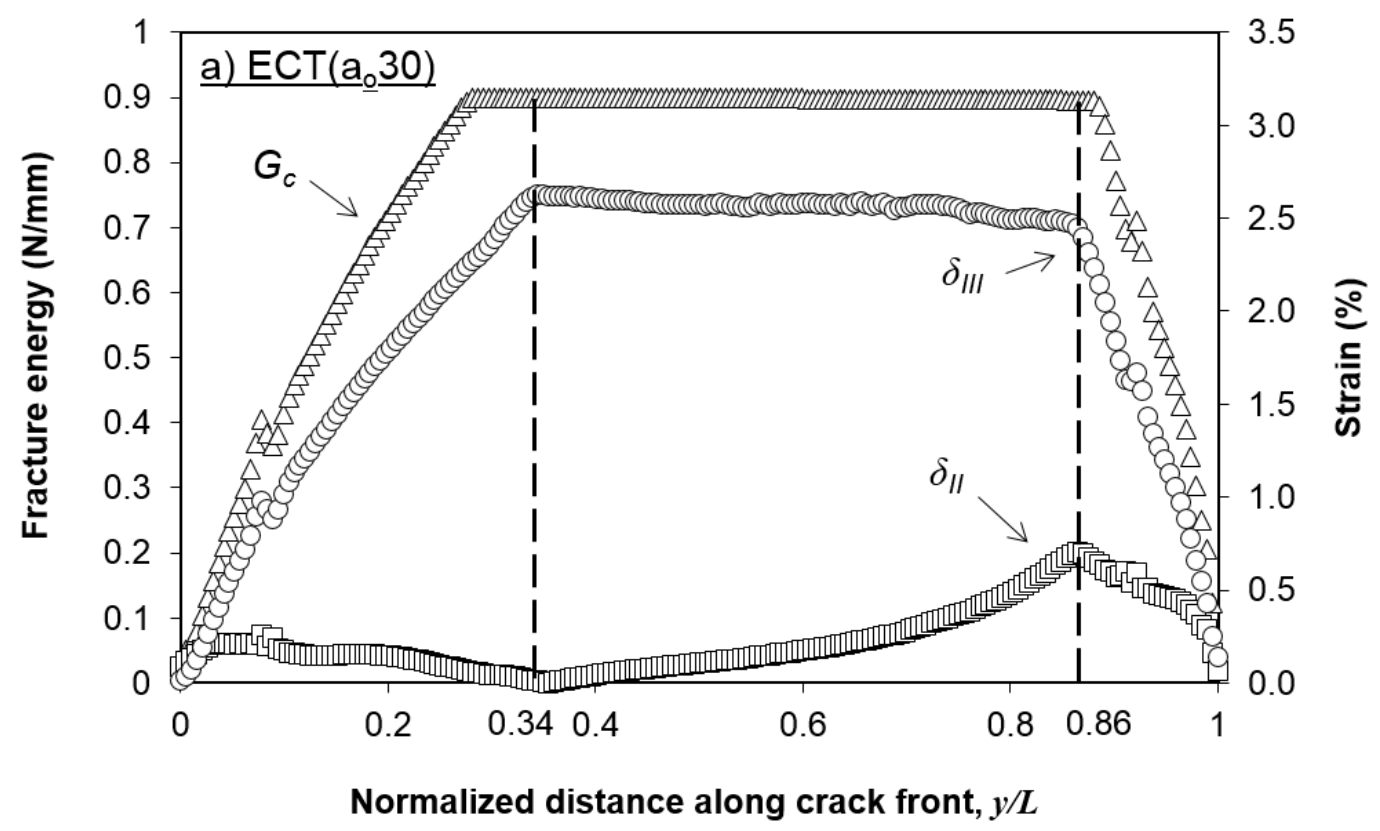

Figure 8. Fracture energy and strain distributions along the crack front

\section{CONCLUSIONS}

In this study, the mode III delamination behaviour of an ECT specimen was simulated using cohesive elements. Based on the simulation results from this study, it is proposed that for an accurate simulation of the mode III interlaminar fracture using the ECT specimen at a reasonable computational time, it was suggested to use a $0.5 \mathrm{~mm}$ mesh size, which provided three elements in the cohesive zone, interface strength of $80 \mathrm{MPa}$, viscosity parameter as $1 \times 10^{-3}$ and interface stiffness with a value of $4 \times 10^{6} \mathrm{MPa} / \mathrm{mm}$.

In addition, it was observed that the delamination was started from a normalised location of approximately 0.7 along the crack front. Furthermore, the fracture energy distribution was found to be similar to the fracture process zone (FPZ) contour. Through strain distribution plots, it was also noticed that the delamination in the ECT specimen was mode III dominated. The numerical results from this study have provided a guideline on how to accurately simulate mode III delamination behaviour of an ECT specimen. This study could be further extended to different types of materials and initial crack lengths for the generalisation of the numerical model.

\section{ACKNOWLEDGEMENTS}

This work is supported by Ministry of Higher Education Malaysia and Universiti Teknologi Malaysia through Fundamental Research Grant Scheme (FRGS) No. 4F591. The numerical simulations were carried out at Computational Solid Mechanics Laboratory, Faculty of Mechanical Engineering, Universiti Teknologi Malaysia. 


\section{REFERENCES}

[1] Wang SS. Fracture mechanics for delamination problems in composite materials. Journal of Composite Materials. 1983;17:210-23.

[2] Szekrényes A. The influence of crack length and delamination width on the modeiii energy release rate of laminated composites. Journal of Composite Materials. 2011;45:279-94.

[3] Khoshravan MR, Moslemi M. Investigation on mode iii interlaminar fracture of glass/epoxy laminates using a modified split cantilever beam test. Engineering Fracture Mechanics. 2014;127:267-79.

[4] Browning G, Carlsson LA, Ratcliffe JG. Modification of the edge crack torsion specimen for mode iii delamination testing. Part ii - experimental study. Journal of Composite Materials. 2011;45:2633-40.

[5] Mehrabadi FA, Khoshravan M. Mode iii interlaminar fracture and damage characterization in woven fabric-reinforced glass/epoxy composite laminates. Journal of Composite Materials. 2013;47:1583-92.

[6] Pereira AB, de Morais AB, de Moura MFSF. Design and analysis of a new sixpoint edge crack torsion (6ect) specimen for mode iii interlaminar fracture characterisation. Composites Part A: Applied Science and Manufacturing. 2011;42:131-9.

[7] Johnston AL, Davidson BD, Simon KK. Assessment of split-beam-type tests for mode iii delamination toughness determination. International Journal of Fracture. 2014;185:31-48.

[8] Davidson BD, Sediles FO. Mixed-mode i-ii-iii delamination toughness determination via a shear-torsion-bending test. Composites Part A: Applied Science and Manufacturing. 2011;42:589-603.

[9] Johnston AL, Davidson BD. Intrinsic coupling of near-tip matrix crack formation to mode iii delamination advance in laminated polymeric matrix composites. International Journal of Solids and Structures. 2014;51:2360-9.

[10] López-Menéndez A, Viña J, Argüelles A, Rubiera S, Mollón V. A new method for testing composite materials under mode iii fracture. Journal of Composite Materials. 2016;50:3973-80.

[11] Reeder JR. 3d mixed mode delamination fracture criteria - an experimentalist's perspective. Proceedings of American Society for Composites, 21st Annual Tehnical Conference. Dearborn, MI, US2006.

[12] Zhao D, Wang Y. Mode iii fracture behavior of laminated composite with edge crack in torsion. Theoretical and Applied Fracture Mechanics. 1998;29:109-23.

[13] Turon A, Dávila CG, Camanho PP, Costa J. An engineering solution for mesh size effects in the simulation of delamination using cohesive zone models. Engineering Fracture Mechanics. 2007;74:1665-82.

[14] Ratcliffe JG. Characterization of the edge crack torsion (ect) test for mode iii fracture toughness measurement of laminated composites. 2004.

[15] de Morais AB, Pereira AB, de Moura MFSF, Magalhães AG. Mode iii interlaminar fracture of carbon/epoxy laminates using the edge crack torsion (ect) test. Composites Science and Technology. 2009;69:670-6.

[16] Salleh Z, Yusop MYM, Rosdi MS. Mechanical properties of activated carbon (ac) coir fibers reinforced with epoxy resin. Journal of Mechanical Engineering and Sciences. 2013;5:631-8. 
[17] Asgari Mehrabadi F. Analysis of pure mode iii and mixed mode (iii + ii) interlaminar crack growth in polymeric woven fabrics. Materials \& Design. 2013;44:429-37.

[18] Nazirah ZS, Abdul Majid MS, Daud R. Effects of elevated temperatures on glassreinforced epoxy pipes under multi-axial loadings. Journal of Mechanical Engineering and Sciences. 2016;10:1846-56.

[19] Ravi Sankar H, Srikant RR, Vamsi Krishna P, Bhujanga Rao V, Bangaru Babu P. Estimation of the dynamic properties of epoxy glass fabric composites with natural rubber particle inclusions. International Journal of Automotive and Mechanical Engineering. 2013;7:968-80.

[20] Jeffrey KJT, Tarlochan F, Rahman MM. Residual strength of chop strand mats glass fiber/epoxy composite structures: Effect of temperature and water absorption. International Journal of Automotive and Mechanical Engineering. 2011;4:504-19.

[21] Xie D, Waas AM. Discrete cohesive zone model for mixed-mode fracture using finite element analysis. Engineering Fracture Mechanics. 2006;73:1783-96.

[22] Zhao L, Gong Y, Zhang J, Chen Y, Fei B. Simulation of delamination growth in multidirectional laminates under mode $\mathrm{i}$ and mixed mode $\mathrm{i} / \mathrm{ii}$ loadings using cohesive elements. Composite structures. 2014;116:509-22.

[23] LeBlanc LR, LaPlante G. Experimental investigation and finite element modeling of mixed-mode delamination in a moisture-exposed carbon/epoxy composite. Composites Part A: Applied Science and Manufacturing. 2016;81:202-13.

[24] Nguyen N, Waas AM. A novel mixed-mode cohesive formulation for crack growth analysis. Composite structures. 2016;156:253-62.

[25] de Moura MFSF, Fernandez MVC, de Morais AB, Campilho RDSG. Numerical analysis of the edge crack torsion test for mode iii interlaminar fracture of composite laminates. Engineering Fracture Mechanics. 2009;76:469-78.

[26] de Morais AB, Pereira AB. Mode iii interlaminar fracture of carbon/epoxy laminates using a four-point bending plate test. Composites Part A: Applied Science and Manufacturing. 2009;40:1741-6.

[27] Camanho PP, Davila CG, de Moura MFSF. Numerical simulation of mixed-mode progressive delamination in composite materials. Journal of Composite Materials. 2003;37:1415-38.

[28] Sørensen BF, Goutianos S, Jacobsen TK. Strength scaling of adhesive joints in polymer-matrix composites. International Journal of Solids and Structures. 2009;46:741-61.

[29] Harper PW, Sun L, Hallett SR. A study on the influence of cohesive zone interface element strength parameters on mixed mode behaviour. Composites Part A: Applied Science and Manufacturing. 2012;43:722-34.

[30] Mollón V, Bonhomme J, Elmarakbi AM, Argüelles A, Viña J. Finite element modelling of mode $\mathrm{i}$ delamination specimens by means of implicit and explicit solvers. Polymer Testing. 2012;31:404-10.

[31] Daniel IM, Ishai O. Engineering mechanics of composite materials. 2nd ed. New York: Oxford University Press; 2006.

[32] Krueger R. Development and application of benchmark examples for mode ii static delamination propagation and fatigue growth predictions. 2011.

[33] Chen J, Ravey E, Hallett S, Wisnom M, Grassi M. Prediction of delamination in braided composite t-piece specimens. Composites Science and Technology. 2009;69:2363-7. 
[34] Allix O, Blanchard L. Mesomodeling of delamination: Towards industrial applications. Composites Science and Technology. 2006;66:731-44.

[35] Zhao L, Gong Y, Qin T, Mehmood S, Zhang J. Failure prediction of out-of-plane woven composite joints using cohesive element. Composite Structures. 2013;106:407-16.

[36] Johar M, Israr HA, Low KO, Wong KJ. Numerical simulation methodology for mode ii delamination of quasi-isotropic quasi-homogeneous composite laminates. Journal of Composite Materials. 2017:0021998317695414.

[37] Islam MR, Beg MDH. Effects of reinforcing arrangement of kenaf fibres into unsaturated polyester for improved properties. Journal of Mechanical Engineering and Sciences. 2016;10:2020-30.

[38] Ismail AE, Che Abdul Aziz MA. Tensile strength of woven yarn kenaf fiber reinforced polyester composites. Journal of Mechanical Engineering and Sciences. 2015;9:1695-704.

[39] Fahmi I, Abdul Majid MS, Afendi M, Helmi EA, M Haameem JA. Low-velocity impact responses of napier fibre/polyester composites. International Journal of Automotive and Mechanical Engineering. 2016;13:3226-37.

[40] M Haameem JA, Abdul Majid MS, Afendi M, Haslan M, Fahmi I. Alkali treatment and thermal properties of napier grass fibres. International Journal of Automotive and Mechanical Engineering. 2016;13:3238-47.

[41] Fajrin J, Zhuge Y, Bullen F, Wang H. Flexural behaviour of hybrid sandwich panel with natural fiber composites as the intermediate layer. Journal of Mechanical Engineering and Sciences. 2016;10:1968-83. 